\title{
Procedure and Care in the Exodontia of Molars in Albino Rats for Experimental Purposes
}

\author{
Masis Hovsepian-Khatcherian ${ }^{1, *}$, Mariana Villarroel-Dorrego², and Marlin Márquez ${ }^{3}$ \\ ${ }^{1}$ Dentist, Orthodontist, Associate Professor, Universidad Central de Venezuela, Venezuela \\ ${ }^{2}$ Dentist, MSc Stomatological Medicine, PhD Oral and Maxillofacial Pathology, Universidad Central de Venezuela, Venezuela \\ ${ }^{3}$ Veterinarian Doctor, Head of the Biotherium of the School of Medicine J.M.Vargas, Universidad Central de Venezuela, Venezuela
}

*Corresponding author: Hovsepian-Khatcherian M, Dentist, Orthodontist, Associate Professor, Universidad Central de Venezuela, Venezuela, E-mail: masis2000@yahoo.com

Received: 22 Nov, 2019 | Accepted: 16 Dec, 2019 | Published: 20 Dec, 2019

Citation: Hovsepian-Khatcherian M, Villarroel-Dorrego M, Márquez M (2019) Procedure and Care in the Exodontia of Molars in Albino Rats for Experimental Purposes. Int J Dent Oral Health 6(1): dx.doi.org/10.16966/2378-7090.310

Copyright: (C) 2019 Hovsepian-Khatcherian M, et al. This is an open-access article distributed under the terms of the Creative Commons Attribution License, which permits unrestricted use, distribution, and reproduction in any medium, provided the original author and source are credited.

\section{Summary}

The laboratory rats offer a mammalian system model characterized functionally and serve as standard organism for the analysis of an important number of biomedical features: cardiovascular, metabolic, neurological, neurobehavioral diseases, organ transplantation, autoimmune diseases, cancer, renal diseases, etc. They offer a number of advantages for the modeling of human diseases, developing new therapies and in the study of responses to environmental agents [1]. Molar exodontia is frequent in albino rats for experimental purposes and because the literature is not very detailed in the exodontia procedures it is decided to carry out this work in order to provide useful information to researchers who need to perform this procedure and thus cause less stress and suffering in the animals used. This work is based on a study to evaluate the effects of unilateral mastication on the temporomandibular joint using as animal model rats to which exodontia of posterior teeth was practiced, previous endorsement of the Bioethics Committee of the Faculty of Dentistry of the Central University of Venezuela (U.C.V.). The experimental work was carried out in the JM Vargas School of Medicine of the U.C.V. Pilot tests were carried out on animals 5 weeks old and after having faced the first contact and having refined the technique, 21 Wistar rats were used. The Wistar rat is currently one of the most popular strains of albino rats used for laboratory research. It is characterized by its wide head, long ears, and with a tail length that is always shorter than its body length. The Sprague Dawley rat and Long-Evans strains of rats were developed from Wistar rats. Wistar rats are more active than other strains such as Sprague Dawley rats. Wistar rats are rats belonging to the species Rattusnorvegicus and were developed at the Wistar Institute in 1906 for use in biological and medical research $[2,3]$.

\section{Dentition of Rats}

The dental formula in rodents varies, but in general they have four incisors, do not have canines, a few premolars and between 8 and 12 molars [4]. The dental formula of albino rats has 2 upper incisors, two lower incisors and 12 molars ( 3 for each half dental arch) do not have canines or premolars, they have single dentition (Figure 1). The period of dental eruption lasts approximately $31 / 2$ weeks and begins with the incisors 8-10 days after birth, the first and second molars between 19 and 21 days respectively, period after which the animals have independent feeding, the third molars do not appear until day 35 . The incisors are four and are the longest teeth in the rat's mouth. The upper incisors are shorter and yellower than the lower incisors. The upper teeth are about $4 \mathrm{~mm}$ long and $1.5 \mathrm{~mm}$ wide while the lower teeth are about $7 \mathrm{~mm}$ long and $1.2 \mathrm{~mm}$ wide.

The upper molars in the Wistar rat are in contact with the maxillary sinus and the incisors are essential for food and quality of life [5,7].
The incisors have a constant growth, the upper ones of the adult rat grow on average approximately $2.2 \mathrm{~mm}$ per week $(0.31$ to $0.32 \mathrm{~mm}$ per day), and the lower incisors grow approximately $2.8 \mathrm{~mm}$ per week ( $0.4 \mathrm{~mm}$ per day) [8]. The molars of the rat are abrasive teeth located at the back of the mouth. They are wide, flat teeth without pigments that grind food into a pulp before ingestion (Figure 2).

\section{Stress and communication between animals}

Several lines of evidence indicate that rodents emit vocalizations in response to a wide range of stimuli that are capable of producing euphoric (positive) or dysphoric (negative) emotional states and to coordinate social interactions $[9,10]$. Among these sonorous emissions are the ultrasounds by means of which the animals communicate with each other, these are not audible by humans. If procedures or manipulations are being performed in a room where animals are housed, it will be noticed that the last ones treated will be more altered. Because of this, it is recommended to have a separate 

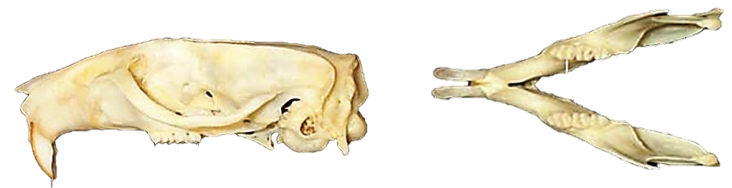

Figure 1: Skull and jaw of an Albino Rat showing dentition [6].

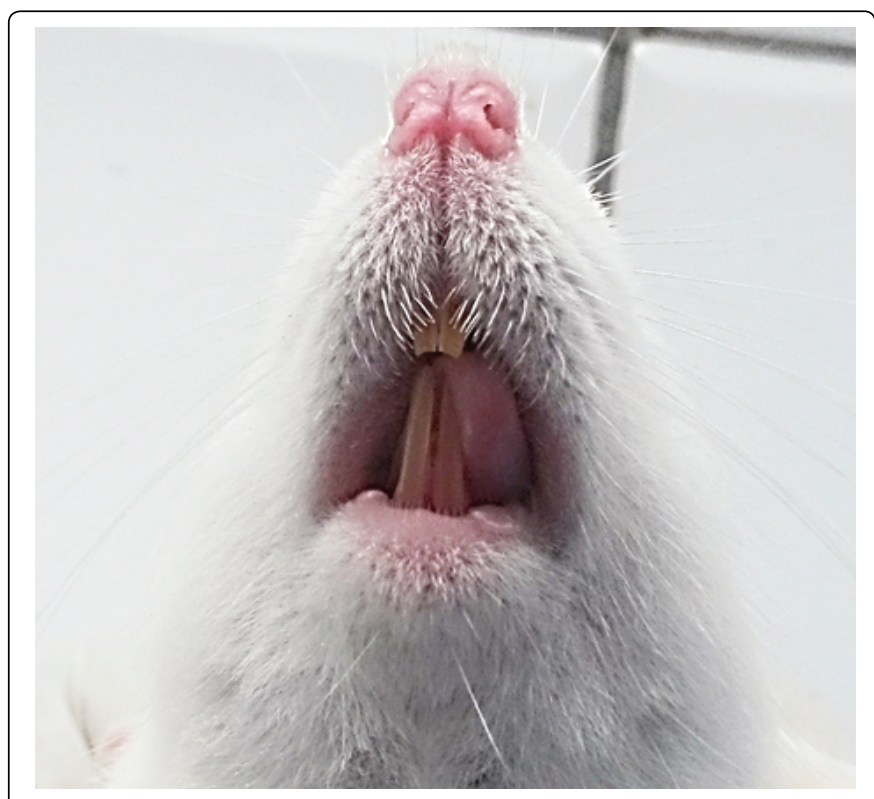

Figure 2: Upper and Lower Incisors of Wister rat.

space from the room where they are housed to perform handling and restraining procedures, for example to administer particular a substance or take samples, to prevent all animals from feeling the stress of a few. Also, if more than one cage or a animal is to be worked with, care should be taken to move only the cage or the animal to be handled to the procedure [11] site. During the exodontia procedures performed in this work, groups of 4 rodents were moved to the operating room in individual cages and these showed an attitude of isolation and fear after the surgical procedure was performed on the first experimental animal, possibly because of the above. In this sense it is important to take the described forecast.

\section{Anesthesia}

General anesthesia is the rule for dental surgery procedures on pets in this sense there are no local anesthesia procedures described in rodents or lagomorphs [12]. The peritoneal route allows a rapid uptake of injected drugs, its disadvantages and potential risks include pain, peritoneal irritation and perforation of an abdominal organ [13]; some of the risks depend on the experience of the operator. Intramuscular injections can cause complications such as tissue irritation, lameness and self-mutilation [14].

In the pilot procedure performed in this study, the intraperitoneal route was used; however, in the experimental procedure, the intramuscular route was used in the posterior muscles of the thigh to avoid the possible erratic emptying of the drug through the intraperitoneal route, since it cannot be assured that the dose is falling into the peritoneal cavity or, in its defect, into the intestine, urinary bladder or another organ as has been reported [15].
Rats are unable to vomit [16]; in this sense absolute preoperative fasting is not necessary before the anesthesia procedure, however, if fasting is employed the limit is no more than two to three hours due to the high metabolic rate of small rodents. Water should never be restricted. Rats vary significantly in their sensitivity to various anesthetics. Age, body composition, stress, health status, genetic manipulation, and sex are just a few of the factors that can contribute to anesthetic sensitivity. The following doses are general guidelines that may vary significantly depending on the factors mentioned above. It is advisable to provide a range that allows titration for the specific needs of each animal.

Ketamine is a general anesthetic of widespread use in veterinary clinical practice and its most notable characteristic is the production of a single state of anesthesia characterized by the dissociation and disconnection of the patient with his environment, maintains the swallowing reflex and produces muscular stiffness so it is combined with a sedative, it is also associated with the production of secretions. Xylazine is a sedative and analgesic that enhances the action of most anesthetic drugs in some species acts as hypnotic and usually produces a mild to moderate analgesia [17].

- Dosage: ketamine: $40-90 \mathrm{mg} / \mathrm{kg}+$ xylazine $5-10 \mathrm{mg} / \mathrm{kg}$

- Route: Intraperitoneal (IP)

- Duration of anesthesia: 45-90 minutes.

If additional anesthesia is needed, reinforce with $1 / 3$ of the ketamine dose only. Xylazine can be reversed with 1-2 mg/kg of yohimbine IP or $0.1-1.0 \mathrm{mg} / \mathrm{kg}$ of atipamezol IP/SQ.14.

During the experimental phase of this research work the animals were administered 10 minutes before anesthesia by subcutaneous Atropine Sulfate in doses of $0.1 \mathrm{mg} / \mathrm{Kg}$ in order to reduce salivation and prevent bradycardia associated with anesthesia, then was used the dose of $50 \mathrm{mg}$ Ketamine/Kg (Heber Biotec ${ }^{\circledR}$ ) and $5 \mathrm{mg}$ Xilazine/Kg (Seton ${ }^{\oplus}$.), Laboratories Calier)) intramuscular in 8 animals producing cardiac arrest in two of them reason why in the remaining 13 animals $40 \mathrm{mg}$ of ketamine/Kg and $5 \mathrm{mg}$ of Xilazine/Kg was applied without presenting mortality allowing the accomplishment of the exodontia of molars and a time of work of 30 minutes approximately, nevertheless it is probable that this dose was the effective one for being animals of low weight. Other combinations

\section{Ketamine+diazepam}

- Dosage: ketamine: 40-80 mg / kg+diazepam: 5-10 mg/kg

- Path: IP

- Duration of anesthesia: 20-30 minutes.

\section{Pentobarbital}

- Dosage: $40-50 \mathrm{mg} / \mathrm{kg}$

- Path: IP

- Duration of anesthesia: 80-90 minutes.

Sufficient dose to produce surgical anesthesia can cause severe respiratory depression and death. Administer diluted in saline solution $(<10 \mathrm{mg} / \mathrm{ml})$. Avoid concomitant administration of buprenorphine. Buprenorphine and pentobarbital will result in cardiorespiratory depression. Administer buprenorphine after full recovery [14].

\section{Cares}

All medications such as anesthetics, analgesics, etc. were previously calculated in tables according to weight in grams to avoid errors, at no 
point in the experimental phase was immediate calculation made. The medicines were titrated in distilled water to adjust them to the weight of the animal. Rat eyes remain open under anesthesia. This can lead to corneal drying and trauma. A drop of artificial tears was applied to each eyeball. Regardless of the anesthetic administered, rats should be monitored under anesthesia to avoid excessive depression of cardiac and respiratory functions, or insufficient anesthesia. Parameters that can be monitored in an anesthetized rat without specialized equipment includes: Anesthetic depth: finger pinch. Respiratory frequency and pattern: normal undisturbed frequency is $\sim 70-120 / \mathrm{min}$; a slow drop in frequency of $50 \%$ is acceptable during anesthesia. Mucous membrane color: should be pink, not blue or gray. Body temperature: can be controlled with a rectal thermometer and should be between 96.5 and $99.5^{\circ} \mathrm{F}$. All species are at risk of hypothermia while under anesthesia. Rats are particularly susceptible. Hypothermia induces significant physiological stress in animals that can prolong recovery and potentially be fatal. Provide supplemental heat during all anesthetic events [14] Warmth was also provided until recovery from anesthesia (Figure 3).

\section{Fluid Support}

$1 \mathrm{cc}$ subcutaneous saline was administered during the surgical procedure. As far as the administration of medications and fluids is concerned, needle gauges and fluid doses must be respected and tables 1 and 2 were applied.

\section{Analgesia}

During the pilot procedures, the non-steroidal anti-inflammatory Flunixin Meglumine was administered at a dose of $1.1 \mathrm{mg} / \mathrm{kg}$ animal subcutaneously. In one of the animals was administered Acetaminophen pediatric syrup in doses of $100 \mathrm{mg} / \mathrm{kg}$ dissolved in drinking water depending on the amount of measured water they drank daily, however after the incorporation of the drug in the water the animal did not consume it so this option was discarded. In the experimental procedure of exodontia a single dose of $1.1 \mathrm{mg} / \mathrm{kg}$ of Flunixin was administered, the animals did not show signs of pain or inflammation in the postoperative period and they were quickly incorporated into the solid diet. Other reported analgesics are shown in table 3.

\section{Exodontia procedure}

For this research work, the guideline procedure was unilateral

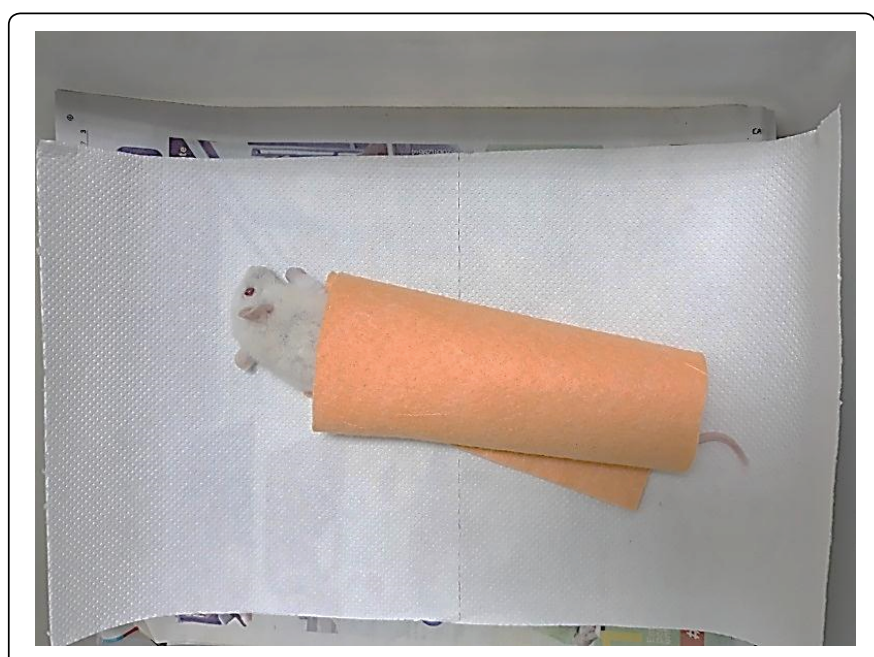

Figure 3: Prevention of post-anesthesia hypothermia with blankets. exodontia of the right side of the three lower molars and first and second upper molars in the pilot study, and in the experimental study, unilateral exodontia of the three upper molars was performed. The complete extraction of a rat molar is not a simple matter due to a large amount of cellular cement that forms rapidly in the apical portion of the root after 40 to 60 days of age. The roots break easily during extraction in animals older than 60 days. The jaw of these animals has high bone density and strength, this also makes the exodontia of the molars difficult, with a propensity to root fracture 7.21, and coupled with it the accessibility of the mouth is very poor in most rodents [12]. The uses of surgical magnifiers $2.5 \mathrm{X}$ and surgical lamp of the operating room facilitated the visual field.

In the pilot phase of this work, the exodontia was tested in two positions, dorsal decubitus and ventral decubitus. The dorsal decubitus position has been reported as $[7,20]$ and seems to be appropriate, however in this case it was not the most suitable since the animal's jaw is depressed and moves to the action of the force of dental luxation and showed little operative visual field. The most suitable ventral decubitus position was determined; the visibility was greater for both the upper and lower jaws. The animal was fixed to an operations board with adhesive tape on its extremities after checking the complete action of the anesthetic by means of a pinch reflex on its legs. The mouth opening was made with elastic threads which were passed behind the upper and lower teeth similar to the technique described by Zecchin KG, et al. [21] and were fixed to bronze pins welded to a ring of orthodontic steel wire caliber 0.045 . The mouth opening was not forced and the elastic threads were stretched to provide a visual field without muscle resistance (Figure 4).

The use of springs made with orthodontic wire $0.7 \mathrm{~mm}$ in diameter with loops passing through the incisors can be useful for the mouth opening. The mandibular support on the surface is fundamental. In the same way, an auxiliary supported the head of the animal at all times, since it moved with the luxation movements when anesthetized. In the

Table 1: Needle gauge for administration of substances via the various routes [15].

\begin{tabular}{|l|c|c|c|c|c|}
\hline \multicolumn{2}{|l|}{ Species Intradermal } & \multicolumn{2}{|c|}{$\begin{array}{c}\text { Subcutaneous } \\
\text { Intramuscular }\end{array}$} & \multicolumn{2}{c|}{$\begin{array}{c}\text { Intravenous } \\
\text { Intraperitoneal }\end{array}$} \\
\hline Mice & $27 G$ & $25 G$ & $27 G$ & $26-28 G$ & $25-27 G$ \\
\hline Rat & $27 G$ & $25 G$ & $25 G$ & $25-27 G$ & $23-25 G$ \\
\hline
\end{tabular}

Table 2: Fluid administration volumes in rats (maximum tolerable)*[18].

\begin{tabular}{|c|c|c|c|c|c|c|}
\hline Routes & Oral & Subcutaneous & I.P. & I.M. & $\begin{array}{c}\text { I.V. } \\
\text { (Boluses) }\end{array}$ & $\begin{array}{c}\text { I.V. } \\
\text { Slow }\end{array}$ \\
\hline $\begin{array}{c}\text { Volumes } \\
(\mathrm{ml} / \mathrm{Kg})\end{array}$ & $10(40)$ & $5(10)$ & $10(20)$ & $0,1(0,2)^{+}$ & 5 & 25 \\
\hline
\end{tabular}

*For aqueous injections, the absorption time should be considered before redoing. No more than two intramuscular injections can be administered per site per day. Subcutaneous injections cannot be more than three per site per day.

+Values per milliliter per injection site. In brackets the maximum doses.

Table 3: Anti-inflammatory analgesics used on rats [19].

\begin{tabular}{|l|c|l|c|}
\hline \multicolumn{1}{|c|}{ Agent } & Doses & Via & Frequency \\
\hline Flunixin & $1,1 \mathrm{mg} / \mathrm{Kg}$ & subcutaneous & each $12 \mathrm{~h}$ \\
\hline Kethoprofen & $5 \mathrm{mg} / \mathrm{Kg}$ & subcutaneous & each $12-24 \mathrm{~h}$ \\
\hline Carprophen & $2,5-5 \mathrm{mg} / \mathrm{Kg}$ & subcutaneous & each $12-24 \mathrm{~h}$ \\
\hline Acetaminophen & $100-300 \mathrm{mg} / \mathrm{Kg}$ & Oral & each $4 \mathrm{~h}$ \\
\hline
\end{tabular}


lateral sense, it is useful for retraction to use a cement spatula bent at a 90-degree angle, since it allows the length of the snout to reach a depth close to the last molar (Figure 5). The mouth floor is to be taken care of, it is very high and there is a frenulum very close to the first molar. The action of atropine reduces salivation so that the instruments stick easily to the oral tissues; this reduces time in the procedure so it was useful to apply a lubricating gel based on carboxymethyl cellulose. As a prophylaxis, a sweep was previously performed with Peridont $0.12 \%$ Chlorhexidine Gluconate solution. The crowns of the molars are short and converge towards occlusal so the tweezers to take them slide easily, the dental luxation must occur previously to be able to take the teeth with mosquito tweezers. The literature describes the luxation with Hollemback [22] spatulas, however this one was not useful to us since for more fine that was the spatula this one was insinuated little in the interdental spaces which present a wide facet of contact, between the dental instruments that were tested the one that was more suitable in our case was the endodontic explorer, its edge and thinness allowed to apply it in the interdental space and to insinuate

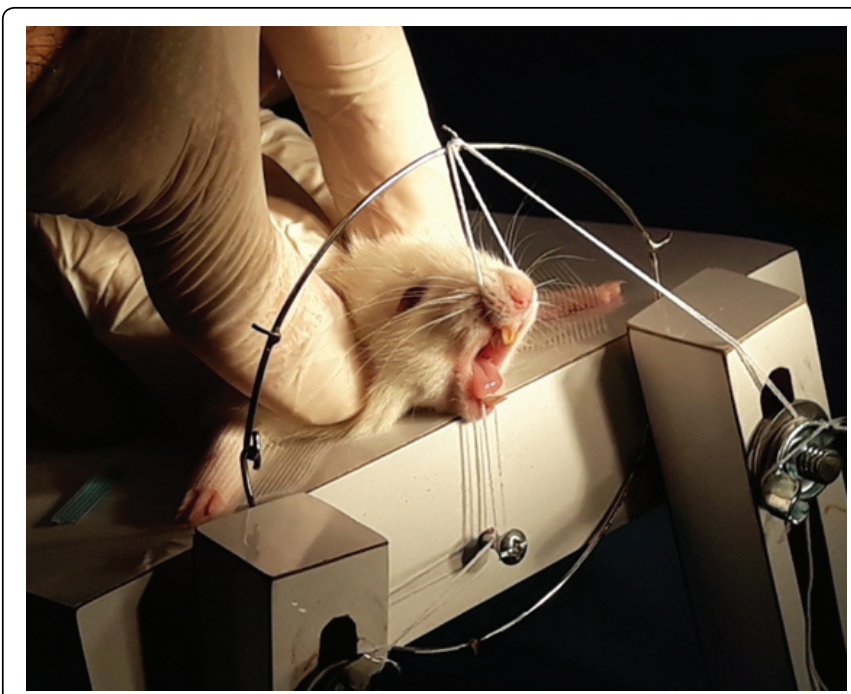

Figure 4: Mouth opening in Wister rat with elastic threads and steel ring with pins.

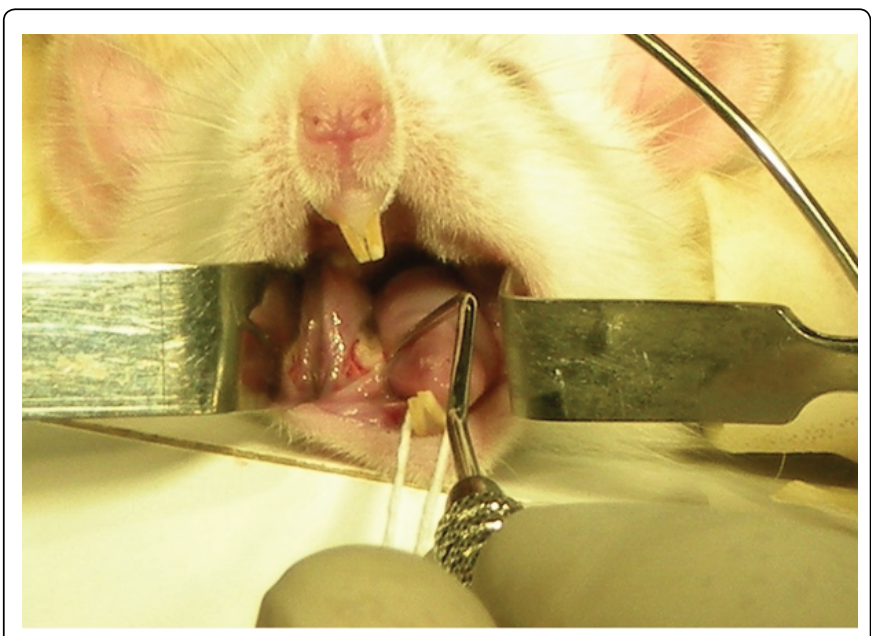

Figure 5: Application of endodontic explorer for exodontia of mandibular molars and use of retractors made with cement spatulas bent at $90^{\circ}$. it between the roots. The instrument allows the syndesmostomy to be performed must be insinuated with an inclination of $45^{\circ}$ from coronal to gingival. The teeth with the most difficulty for extraction are the first lower molar and the first upper molar, the lower one has a greater volume but was extracted in a simple way. It has also been described the extraction of this molar by means of dental partition with round drill $1 / 4$ what facilitates the procedure by the great dental volume [21]. The endodontic explorer can also be insinuated from vestibular and lingual in the interradicular spaces and by means of lever action make luxation. The opposite side to the luxation must be protected by the application of a spatula; a sufficient amount of force must be applied to perform the luxation, the instrument slides easily and can lacerate the mouth floor in the mandibular case and other surrounding tissues in the upper jaw (Figure 6). We do not recommend performing the exodontia with mosquito forceps without previously performing the luxation with the fine instruments described since the short crown of the molars leads to the application of great force for the subjection of the tooth, which causes the fracture of the tooth and must therefore cause prior luxation. After this, the tooth can be taken with mosquito tweezers and the teeth can be properly extracted.

Once the exodontia of the first molar has been carried out, subsequent molars are extracted more easily. The endodontic explorer can be applied from the mesial of the second molars through the alveolus left by the first molar and applied between the vestibular and lingual roots and levering vertically with support in the interdental alveolar bone and in this same way for the third molar in combination with the technique of luxation from vestibular, lingual and interproximal. In few cases the crown was fractured and in this situation the roots were extracted without complication with the same endodontic explorer. Usually the teeth were extracted completely (Figure 7). Followed by

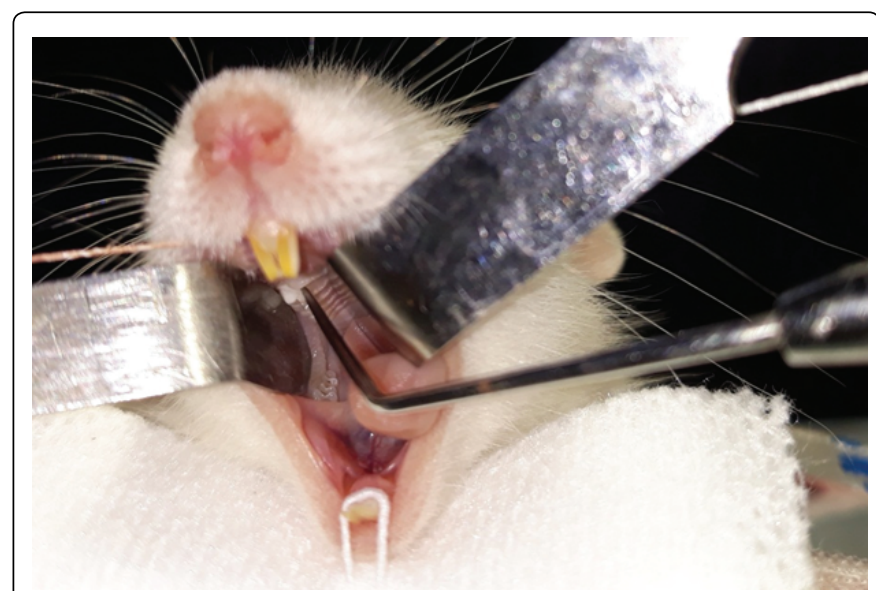

Figure 6: Endodontic explorer application for molar exodontia in upper jaws.

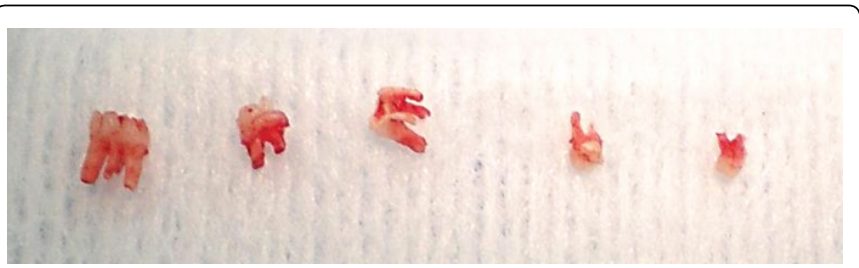

Figure 7: Dental samples from 5-week-old Wister rats.

From left to right first and second mandibular molar, first second and third maxillary molar. 
the anesthetic recovery period the animals showed no signs of trauma and were quickly incorporated into the solid pellet diet. Some authors drill the alveolus with drill No. 2 to remove possible root debris [7].

Although in this experiment no incisor exodontia was performed, the use of hypodermic needles has been described. The beveled end of the needle efficiently cuts the ligament. The needle can also be bent to follow the curvature of the tooth. The use of elevators and forceps in rats has also been reported in incisors [23-25].

\section{Conclusions}

The use of albino rats for experimental purposes is frequent and exodontic procedures are common in this work. Exodontia in these animals is not easy due to the great apposition of cellular cement in their roots. The use of general anesthesia is the rule for this procedure and a protocol of care must be followed during the surgical procedure to monitor the vitality of the animal. The adequate positioning of the animal in ventral decubitus and a mouth opening with elastic threads facilitates the procedure. In this study it was determined that the use of the endodontic explorer is ideal for dental luxation prior to exodontia with mosquito forceps, providing little trauma and a quick incorporation to solid food.

\section{References}

1. Hedrich HJ (2000) History, Strains and Models. In: Krinke GJ (eds) The laboratory rat. Academic Press 3-16.

2. Clause BT (1998) The Wistar Institute Archives: Rats (Not Mice) and History. Mendel Newsl 7: 2-7.

3. Laboratorio de ensayos biológicos. Universidad de Costa Rica.

4. Legendre LF (2003) Oral disorders of exotic rodents. Vet Clin North Am Exot Anim Pract 6: 601-628.

5. Weijs WA (1975) Mandibular movements of the albino rat during feeding. J Morphol 145: 107-124.

6. Dental Anatomy of Rodents. Vivo Pathophysiology.

7. Moñivas PC, García LP, Arias SP, Izquierdo HA, López CC, et al. (2015) Estudio experimental para la valoración de la cicatrización ósea con Ácido Zoledrónico en ratas Wistar. Sanidad Militar 71: 232-238.

8. Addison WHF, Appleton JL (1915) The structure and growth of the incisor teeth of the albino rat. J Morphol 26: 43-96.

9. Simola N, Granon S (2018) Ultrasonic vocalizations as a tool in studying emotional states in rodent models of social behavior and brain disease. Neuropharmacology 159: 107420.

10. Simola N (2015) Rat Ultrasonic Vocalizations and Behavioral Neuropharmacology: From the Screening of Drugs to the Study of Disease. Curr Neuropharmacol 13: 164-179.

11. Mourelle C, Herrero E, Ricca M (2013) Recomendaciones para manipulación y sujeción de ratas y ratones de laboratorio. Spei Domus 9: 39-47.
12. Vlaminck L, Verhaert L, Steenhaut M, Gasthuys F (2007) Tooth extraction techniques in horses, pet animals and man Extractietechnieken bij het paard, gezelschapsdieren en de mens. Vlaams Diergeneeskundig Tijdschrift 76: 249-261.

13. Levin-Arama M, Abraham L, Waner T, Harmelin A, Steinberg DM, et al. (2016) Subcutaneous Compared with Intraperitoneal KetamineXylazine for Anesthesia of Mice. J Am Assoc Lab Anim Sci 55: 794800.

14. Anesthesia Guidelines: Rats. Academic Health Center Research Services, University of Minnesota.

15. Morton DB, Jennings M, Buckwell A, Ewbank R, Godfrey C, et al. (2001) Refining procedures for the administration of substances. Lab Anim 35: 1-41.

16. Tuerke KJ, Limebeer CL, Fletcher PJ, Parker LA (2012) Double dissociation between regulation of conditioned disgust and taste avoidance by serotonin availability at the 5-HT (3) receptor in the posterior and anterior insular cortex. J Neurosci 32: 13709-13717.

17. Molina Lopez AM, Moyano Salvago MR, Peña Ojeda FJ, Lora Benitez AJ, Moreno Barrientos S, et al. (2008) Depresores del Sistema Nervioso Central y anestesia en roedores de experimentación. Recvet Vol III.

18. Procedimiento de administración de sustancias y toma de muestras sanguíneas incluyendo rutas y volúmenes en roedores de laboratorio. Procedimiento Operativo Estándar.

19. Davis JA (2008) Mouse and rat anesthesia and analgesia. Curr Protoc Neurosci 42: A.4B.1-A.4B.21.

20. Pietrokovski J, Massler M (1967) Ridge remodeling after tooth extraction in rats. J Dent Res 46: 222-231.

21. Zecchin KG, da Silva Jorge R, Jorge J (2007) A new method for extraction of mandibular first molars in rats. Braz J Oral Sci 6: 13441348.

22. Agaçayak KS, Yuksel H, Atilgan S, Koparal M, Uçan MC, et al. (2014) Experimental investigation of relationship between trauma and bisphosphonate-related osteonecrosis. Niger J Clin Pract 17: 559564.

23. Legendre L (2012) Rodent and Lagomorph Tooth Extractions. J Vet Dent 29: 204-209.

24. Pizarro P (2010) Efecto histopatológico de la morinda citrifolia en alveolos post exodoncia de ratas albinas. Tesis, Para obtener el título profesional de cirujano dentista. Universidad Nacional Federico Villarreal. Perú.

25. da Silva Brasilino $M$, Stringhetta-Garcia $C T$, Pereira CS, Pereira AAF, Stringhetta $K$, et al. (2018) Mate tea (Ilex paraguariensis) improves bone formation in the alveolar socket healing after tooth extraction in rats. Clin Oral Investig 22: 1449-1461. 